This is an Accepted Manuscript of a book chapter published by Routledge/CRC Press in The Routledge Companion to Literature and Trauma on May 26, 2020, available online: https://www.routledge.com/The-Routledge-Companion-to-Literature-andTrauma/Davis-Meretoja/p/book/9781138494923

Published version of the chapter: https://doi.org/10.4324/9781351025225-29

\title{
Graphic Narratives as Trauma Fiction
}

\author{
by Katalin Orbán
}

The understanding of psychic trauma evolved over the same hundred years as the modern mass-cultural medium of comics, and the rise of trauma theory coincided with the recognition of comics as a mature medium for serious topics. On that basis alone, one might expect comics to address trauma extensively. Some claim, however, more than coexistence and expected intersections: comics are ideal for representing trauma due to their visual form (Earle 2017: 10) and offer unique opportunities for putting the elements of trauma on view (Kohlert 2015: 124, Chute 2016), thanks to "interesting parallels" between comics layout and structures of traumatic memory (Dony and van Linthout, 2010: 178).

The use of drawing, in particular, can forge a connection between comics and trauma's precarious position between the body and mental life. For the act of drawing foreground the relationship between meaning and its material base differently from photography, as the line is a material trace of physical gestures. Drawing highlights the interplay between recording subjectivity as a fully intentional act and as the contingent material effects of contact, a peculiar, partly unconscious relationship between mental processes and embodied actions that was central to the concept of psychic trauma from 
the start. The shell shock epidemic caused by combat experiences in World War I seemed to originate equally plausibly from the patient's deeply shaken "self-love" and his brain tissue -- observed by the psychiatrist and dissected by the military pathologist (Ferenczi 1994 [1916/17]9:141, Shively \& \& Perl 2012: 235; Geroulanos \& Meyers 2018: 72-74). The modern concept of psychic trauma evolved from these murky investigations almost beyond recognition into the dominant framework for thinking about many kinds of pain and suffering, including more collective, metaphorical, and mediated experiences over the next hundred years. Yet, as a cultural framework, it still straddles a porous divide between mental life and the body, which often animates artistic responses to trauma, but serves as an exceptionally important connection between comics as a medium and the cultural imagination of trauma.

Focusing on book-length works of graphic literature, while remaining attentive to their mass-cultural, commercial contexts, this chapter examines the affinities and key connections between trauma and its characteristic treatment in graphic fictions: divisions of form and selves, frozen images, transformation as a representation of the overwhelmed self, and drawing as a physical gesture tied to sensory memory. This addresses both aspects of comics' affinity with trauma: the visualization of traumatic experience within the gaps, divisions, and heterogeneity of comics and its generation through the mind/body interface, through embodied practices of writing and drawing.

\section{Divisions - Gaps, Parts, Broken Selves}

The page or the double-page tableau, as a layout of simultaneously visible panels, is the unit that structures our reading experience of comics most differently from other narratives, constraining what is accessible to the reader at a single time: "always a space that has been divided up, compartmentalized, a collection of juxtaposed frames" (Groensteen 2009: 130). This divided plane, typically composed of interconnected panels and gutters, can be exploited in the representation of traumatic experience and its aftermath in two major ways: by reflecting the shattering of the normal defenses of the self and its capacity for creating coherent meaning and by reflecting the dissociative defense against trauma through a compartmentalization of experience that reduces its 
availability to consciousness and narrative. Since this division of the visual field is also the primary means of representing time in comics - temporal relationships are spatialized - layouts can creatively represent the temporal delay and persistence of trauma, its retroactive integration and ownership, especially when combined with multiple modes of producing meaning through words and images.

This shattering of the plane is Art Spiegelman's central strategy for responding to the traumatic experience of the September $11^{\text {th }}$ attacks in New York City. In the Shadow of No Towers (2004) is an unusually large book of unusually few pages $(10+7)$. When opened to a series of ten double-page tableaux, the size doubles to a surface of 14 by 20 inches, a vast plane orchestrating a vividly diverse set of micro-narratives in individual panels and partially overlapping short sequences in varying degrees of dynamic disarray. While some mini-stories use a conventional left-right top-down arrangement of equal sized panels, the full arrangement has no uniformity of scale, coloring or style, so the story kernels float like a constellation of narrative debris from the explosion. The visual integrity of the small stories is threatened by panels that collide or detach themselves, and some elements appear to break through the two-dimensional plane: the side view of rotating panels reveals the towers, and the canvas on which someone is painting the burning towers juts out of its panel (Spiegelman 2004: 2, 4).

These divisions inhibit sustained narrative development and scatter attention between the many stories which are started and interrupted, representing a time that refuses to arrange itself into a meaningful continuous experience of unfolding events. Undermining an overall sense of coherence, the many possible sequences and hierarchies within the large tableaus mimic the impact of severe shock. If this invokes trauma as a breach of the normal defenses of the self, it also emphasizes the work of integration, not only in the artist's repeated attempts to retell his experience, but just as crucially in the experiential work of integration imposed on the reader, who has to assemble the pieces rather than simply reading about such assembly. While emphasizing the collapse of self and its ability to represent an overwhelming experience, this departs from a notion of trauma as a pre-linguistic event that is the "ultimate unrepresentable" in the classic model of trauma (Balaev 2014: 5), nor does it excessively question individual autonomy and the ability to express experience. This is because "Trauma piles on trauma!" (Spie- 
gelman 2004: 5) in the very literal sense of multiplicity and layering in the book, creating a surfeit of multi-discursive representation that draws on the specificity of the event (a series of explosions and a multitude of televisual, digital and analog modes of representation surrounding the attacks), rather than any absence or a universal model of dissociation. Although this type of shattering narrative cohesion has at times been critiqued as a modernist cult of "foregrounded difficult and disrupted representation and form" (Luckhurst 2013: 159) and the attendant suspicion of mass cultural forms and the narrative pleasures they offer, this hardly fits Spiegelman's work, which goes to great length to celebrate these pleasures by extensively incorporating historical comics into his work, in fact, taking solace in them in an otherwise inhospitable landscape of rubble and jingoism.

Of course, the same formal characteristics of layout can be used to different effect in narratives of extreme hardship that emphasize agency and resilience above all. For example, in Josh Neufeld's A.D. about the devastation caused by Hurricane Katrina in 2005, the same breaking up of the plane is put in the service of parallel stories, a multivocal assemblage narrative that presents a complex anatomy of disaster with little emphasis on the breakdown of the seven narrating selves, relative to the breakdown and dysfunction of social institutions that should guarantee their safety and well-being. Similarly, their ability to articulate the experience is constrained primarily by the lack of social networks of support and a disinterest in the suffering of less privileged groups rather than by any "assumed inherent neurobiological features of trauma" (Balaev 2014: 1) that work against representation.

In addition to the divisions of layout, comics can make use of the conjunction or disconnection between words and images to represent the absolute or relative unavailability of an experience to consciousness and narrative memory. Since comics spatialize time (shapes, gaps, distances, and sequences showing pace, succession, etc.) while also expressing temporal relations verbally, artists can create a uniquely complex sense of contemporaneous or retrospective articulations and integrations of what happened. Not only can they combine these devices creatively, exploiting their mutual confirmation or conflict, but they can also withhold them, for instance, by eliminating paneling conventions that anchor voices and events in stable positions. This is the ever-changing rich 
variety of the ways graphic narrative accomplishes the tracing of time "in complex, often nonlinear paths across the space of the page" (Chute 2008: 454). Consequently, even when a graphic narrative focuses on traumatic events as hidden, unknown or silenced, its medium often yields a counter-discourse to traumatic absence. The silence modulated into a partial retrospective voicing and visualization through the interactions of verbal and visual narrative tracks can be a reintegration of the narrator's own unacknowledged experiences, as in many survivor narratives. Alternatively, it can be the integration of a previously unknown or silenced traumatic experience through listening, secondary witnessing, and subtly or thoroughly transforming one's own life in the process, as in numerous second-generation family narratives reconstructing events behind a wall of intergenerational silence or disinterest, from Art Spiegelman's post-Holocaust Maus (1986/91) to G. B. Tran's Vietnamerica, (2010), a discovery of exile and loss suffered by the previous generations.

Pseudonymous British artist Una's Becoming Unbecoming (2015) is of the former category, a story of sexual violence juxtaposed with the search for the Yorkshire Ripper. Una's narrative shifts between genres, a composite of personal narrative and educational-political pamphlet, and her experience of abuse and rape is surrounded by a multitude of discourses: the misogynistic discourse that actively silenced her at the time and also drove the dismissive response to the Yorkshire Ripper's serial killings, the emancipatory, therapeutic discourses which serve its delayed acknowledgement and reintegration, and the cautionary discourse that keeps the narrative open and the danger present for others. The latter are voiced not only by her older self, but by an anonymous chorus of outsiders represented by disembodied speech balloons. In the noise created by retrospective narration and commentary, certain images of trauma slow down or halt narration, completely replacing or overwhelming words. These amplify a strategy employed throughout the text: the closer the narrative comes to a traumatic event it recounts, the more it relies on the relative delay between word and image, rendering the reader a party to misrecognition and retroactive understanding. We first see and do not know (a disembodied pair of legs) or first know and only see later (a piece of clothing worn during an attack), and in either case we are prevented from making full sense of a scene until later. 
This disjunction between words and images is even stronger in the images that never show a literal visual representation of what happened to the artist, but rather visualize her solitary work of unknowing and unsaying it. Although she says "I soon learned to lower my gaze," she is shown on her back looking upward, positioned on a rectangular shape like a comics panel, which contains the dark indistinct mass of watercolor wash oozing from her (13). As always, the oozing shapeless form is behind her, physically, materially attached, but invisible to her. She says "life continued," but repeated identical images of her climbing a hill, reeling under an empty bag, an unknown burden, show stasis and repetition (25). Her vacant bag of burden, which eventually darkens with retrospective knowledge, is visually revealed later as the lack of voice: the hill she climbs is shown as a field of sentences - copied from the media coverage of the Ripper case - and her bag is, in fact, an empty speech bubble (57). Divisions and delays between word and image, then, turn these images into the residue of former loneliness and vulnerability, the lingering limit to the delayed explanation and self-possession dominating the book. Instead of embracing trauma's "undying pathological influence on consciousness" (Balaev 2014: 6), this imaging of trauma is always re-enveloped by a voluble commentary of competing voices that shows how much their lasting influence is a matter of social structures and norms. In fact, the equal privileging of aesthetic pleasure and the promotion of social change through the empowerment of past and potential victims of sexual violence also shows that this use of disunity in the representation of trauma need not be a celebration of the difficulty to secure a place for comics in elite culture.

\section{Frozen Images - Arrest and Repetition}

Graphic narratives of trauma often freeze moments that exercise a hold on the protagonist, sometimes through repetition, sometimes through the difficulty of recollection. Such reconstructed mental images and reconstructions or reproductions of photographs transfix characters (or potentially the reader), depending on how the narrative constructs a sense of subjective vision in the given scene through the relation between what is visible in the panels, the point of view established by the narrative and what 
characters see (Mikkonen 2015: 105). They may be seen as intrusive, belatedly experienced returns of the moment as flashbacks or nightmares that break into consciousness and cannot be placed in a sequence. Yet, even though this may only be apparent once they have lost their power, these images tied to the overwhelming traumatic event are frozen moments abstracted from a flow that would have normally proceeded had the subject not been forced to dissociate him- or herself from the event.

The archetype of such an arresting image of horror in comics which is recreated as the unassimilable sight of a particular moment is the narrator seeing the disintegrating living bodies of Hiroshima victims in Nakazawa's "I Saw It" published in 1972 and later in the longer narrative of Barefoot Gen (Nakazawa 1982: 13; 2016: 253-254). It is also, as Hillary Chute explains in Disaster Drawn, a counter-image to the atomic bomb as a technological image imprinted on objects and bodies through irradiation (2016: 136).

Occurring both in narratives of horrific exceptional events and of prolonged abuse, such frozen images can serve as a site of the difficulties of satisfactorily recollecting and representing the experience, of the ultimately unverifiable truth of an experience that proved profoundly disorienting, and of establishing the traumatic nature of an unacknowledged experience.

The most obvious cases of such images are, as in the case of "I Saw It", images of what a survivor actually saw at the moment of shock, either as a remembered or an intrusive image. Spiegelman's In the Shadow of No Towers includes such a repeated image of the glowing Twin Towers before they collapse, and the text describes them both as remembered and intrusive at different times ("We hear a roar like a waterfall, and look back."; "I still see the glowing tower, awesome as it collapses"; "he still sees that glowing tower when he closes his eyes"; "what he actually saw got seared into his skull forever" 1, 4). The glowing image, repeated on every double-page spread, fulfills a dual function: it is an image of a sight that serves as a sign of the event's powerful continued hold on the viewer, and it is a repeated representation that marks the slow integrative work of creating a recollection and a representation commensurate with a near-death event. Trauma narratives often include the inverse or negative of such a persistent traumatic image as well: persistent images that fail to show the traumatic events revealed or im- 
plied through words are central to several narratives about atrocity, genocide, and ecological disaster. La fantaisie des Dieux: Rwanda 1994 recounts the narrator's return to sites of genocide in Rwanda after twenty years. It includes both a traumatic image of a seemingly beautiful, quiet landscape suddenly revealing itself as a landscape of corpses in May 1994 (Hippolyte - Saint-Exupery 2014: 8-11) and numerous inverse images of beautiful, quiet hills and lakes $(20,66-67,82-83)$ refusing or failing to reveal the truth of a "country of silence" (78).

Similarly, Springtime in Chernobyl, Emmanuel Lepage's narrative about his visit to Chernobyl twenty-two years after the disaster, is filled with images of the Exclusion Zone; what transfixes Lepage are the beautiful images of invisible damage in the Zone, a sanctuary undisturbed by human activity that cannot be forced to give up its dark truth (Lepage 2013). ${ }^{1}$ This inverse traumatic image is not a figure of the ultimate inaccessibility of trauma in either case, not only because it is surrounded by extensive survivor memories of the local communities, but also because it is shown to yield to a type of contact that is not reduced to vision -Fantaisie refills the landscape with the witness's memories of victim and perpetrator bodies when he is submerged in Lake Kivu (32-33, 45-47, 59-66), and Springtime visualizes the effect of radioactive landscape on the artist's body physically exposed to radiation.

The protagonist of Joe Sacco's The Fixer (2004) is a former soldier in the war in Sarajevo, whose status as traumatized is deeply complicated by him being an unreliable witness to his past experience, and the uncertainty about how intentional his unreliability is. Is it a structural unreliability of trauma (his memory is impaired due to the very experiences he cannot verify), or an incidental one of fraud (he is a manipulative liar and embellisher). Based on the entire narrative, Neven is probably both: a traumatized teller of tall tales, a manipulative survivor. The image at the center of this vortex of uncertainty is a photograph (reproduced in the book as a drawing) that allegedly shows his comrades. The group photo certainly cannot prove all the unverified and disputed war memories Neven recounts during conversations throughout the book, and by the second time the photo appears they are dead and he can no longer remember their names (34, 100). This can be interpreted as simply an emphasis on the instability and processual

\footnotetext{
${ }^{1}$ An English translation of Un printemps à Tchernobyl entitled Springtime in Chernobyl is forthcoming (San Diego: IDW, 2019) at the time of this writing.
} 
nature of memory (Chute 2016: 230), as the fixity of the photo fails both narratively and visually: its two instances sixty pages and six years apart in the book are not identical. Yet, the photo is also an image-object that signals vulnerability to the suspicion surrounding the trauma victim's lack of self-possession from the start: from the earliest shell shock patients brutalized as presumed malingerers to the most recent debates about inflated numbers of PTSD and the failure of tests to identify "people trying to simulate the symptom pattern factitiously" (Konner 2007: 311).

The most disturbing images of Phoebe Gloeckner's book The Diary of a Teenage Girl are unrepeated traumatic images that arrest the reader not only due to their often graphic nature, but also because they suspend the near normalization of prolonged sexual abuse in a text where the sexual awakening of Minnie, the authorial alter ego, and her abuse by Monroe, her mother's boyfriend, are conflated into a single, inextricable story. The text is difficult reading because the young diarist's perspective and voice make it impossible to distinguish her agency and victimization, making us complicit in failing to acknowledge her traumatic experience if we take her claims of agency and desire at face value and complicit in denying her agency and voice if we reduce her to a victim. The Diary is punctuated by full-page illustrations, including numerous portraits, diverse drawings including diagrams, zoological illustrations, and maps, and numerous comics ranging from single panels to longer stories up to twelve pages in length. Some of these function as traumatic images, freezing moments of the story; while alluding to traditional illustrations of $19^{\text {th }}$-century novels, they are not accompanied by titles naming characters or scenes, but by captions that literally repeat words that appear in the text ("I love Monroe to touch me affectionately" 84) as if confirming their status of frozen image, extracting them from the narrative flow and immobilizing them against the readerly impulse to move on.

These images address, even if they do not fully resolve, the dilemma of agency created by the text: they anchor the text in trauma fiction and give the reader the strongest footing to read the book against the normalization of abuse without demonizing female sexuality. They also introduce their own problem: the reader is once again very uncomfortably positioned as both witness and voyeur, looking at a scene of an adult male touching a teenage girl "affectionately." Through the use of extreme foreshortening 
and internal differences in scale, these images appear somewhat distorted or altered visions of a neutrally observed reality, but they nearly always represent perspectives that could not have been held by the diarist. Thus the frozen images of "what happened" in the diary's words constitute an external vantage point unavailable in those words, a vantage point shared by the adult self and the reader as co-viewers of her experience. We are the dissociated spectators of her experience in a way that she never could be. Never repetitive, these traumatic images not only insert a retrospective self-understanding into the text, but also create a space for an experience ofimmobility, the unsettling impossibility of intervention that only ends when the final moment of declared empowerment, control, and self-worth concludes both the diary and the relationship.

\section{Transformations - Monsters and Animals}

The self vacated in response to the overwhelming power of psychic trauma and the uncontrolled re-living of trauma have inspired fantastic and mythic visions of possession and metamorphosis from the earliest era of shell shock. Both the uncontrolled expressivity of the self and its loss of control to an external agency, embodied memorably in the hypnotically controlled murderous sleepwalker Cesare in the silent horror film The Cabinet of Dr. Caligari (1920), recur in transformative representations of the traumatized self. The plasticity of drawing and the reliance on stylized representations allow comics to develop such transformations with exceptional ease and creative variety, and graphic trauma fictions abound in such altered states, especially in the form of monsters and animals, not only as occasional characters, but as sustained representations throughout entire works. These are also artistic revisions of superhero, sci-fi, horror, and animal comic tropes, especially the linking of self-transformation to a riddle of identity in the superhero's secret identity and the emphasis on their expressive body. Monstrosity as a traumatic transformation can be a revision of the "full-bodied, kinetic performance" enacted by superheroes (Bukatman 2009: 115), except as a reverse superpower which absorbs the transformative impact of shock.

The acknowledgement of this generic history varies in its degree of explicitness, though rarely to the point of complete disavowal. The explicit invocation of Mickey 
Mouse in Art Spiegelman's groundbreaking Maus (1986), using characters with humananimal hybrid bodies in a Holocaust narrative, is amplified to an ostentatious and ironic re-enactment of horror tropes in the pseudo-pulp My Favorite Thing Is Monsters (2017) and muted to a tacit assumption of animal comic models in the "talking dog" character of Deogratias (2006), a narrative about genocide in Rwanda. By contrast, La légèreté, Catherine Meurisse's narrative of recovery after the terrorist attack on Charlie Hebdo, completely disavows this history, adopting a literary and art historical lineage of canonical elite culture (including the Niobe sculpture group in the Villa Medici in Rome, based on a Greek myth of the bereaved mother turned into a rock by Zeus to petrify her feelings).

The use of animals and monsters, particularly the visualized human-animal transformation, in a genocidal or military context visually connects genocidal cause and traumatic impact. Even as the transformation exhibits trauma as a breakdown of the functioning self, it also identifies animalization and monstrosity as an intentional systematic dehumanization that removes agency as a foundation of humanity. The animal image materializes the conversion of an abstract dehumanizing rhetoric (for example, the "animalizing rhetoric of Tutsis as snakes and cockroaches" in Hutu propaganda (Chaney 2011: 93) into acts of murder. Whereas Rupert Bazambanza uses animals primarily as witnesses to genocide in his Smile through the Tears (2005), Stassen's Deogratias has a protagonist that periodically transforms into an animal in a narrative structured as increasingly long interruptions of the present by intrusive memories that take possession of the young boy, who is slowly revealed to inhabit the composite roles of perpetrator, victim, and witness. As Deogratias includes no narration to orient the reader beyond images and dialogue, the traumatization of an unwilling child perpetrator in genocide is conveyed primarily through his recurring transmogrification -- a fantasy of turning into the scavenging, corpse-eating dogs he saw after the killings. Rather than a therapeutic process of integrating unassimilated memory, the transformations chart a descent into self-loss and murderous revenge that repeats rather than integrates his unassimilable past, even as an informative historical context emerges around this vortex through conversations and pre-genocide memories. 
As transformation is meaningful precisely in its dynamic change of self, it does not need to be reduced to a metaphorical screening of horror, with animals as cunning figurative estrangement to overcome the "paralyzing effects" of mimesis, for which Andreas Huyssen once praised Maus (Huyssen 2003: 128). In fact, the question whether animalization is used as a universalizing metaphor is all the more pressing in the visualization of genocide in an African country primarily for Western audiences. Like numerous critics of classic trauma theory, Alan Gibbs notes that abstracting trauma to a generalized structure and a transhistorical concept of absence risks "anaesthetising concrete historical loss" (2014: 205) in the name of an allegedly universally human experience that typically turns out to reflect Western bias (Craps 2014). Relying on the complementary figure of "the human," the use of the animal and the monster can be vulnerable to this critique, but they can also embody contextual values and historically contingent representations of traumatic experience. The scavenging dog, for example, reinscribes the generic animal - a figure of Déogratias's distintegrating self - into a historically specific setting where mass murder took place in public exacerbated by modern mass communication (hate radio), but minimally aided by modern industrial technology. This can be the starting point for asking about the foundations of community, if any, for people between whom "identifications via traumatic sufferings can be forged" (Radstone 2007: 25). Although Deogratias fails to accomplish this, it could in principle engage with colonial representations of Africa, in comics and elsewhere, as the troubling prehistory of its image of transformative shock.

Emil Ferris' My Favorite Thing Is Monsters, presented as a young girl's handwritten, copiously illustrated diary in a blue-lined notebook, is a far more playful, though by no means light, narrative defined by monstrous transformation. It sets up more unstable relations between reality and fantasy and between variant identities through many kinds of mimicry including disguise, ventriloquism, and imitation of representational styles (notebook, horror comic covers for each chapter). It is unclear from the start to what extent the transformative processes are materially real, reflections of psychological states, or the narrator's creative acts of imagination. The detailed description of her physical transformation into a howling werewolf persecuted by a mob turns out to be a recurring dream, from which she wakes, but her waking state does not elimi- 
nate her (self-)representation as a monster. As layers upon layers of reality are peeled back, her precocious detective work keeps uncovering the seedy, immoral underside of normative social order in the Chicago of the 1960 s, where crime, scenes of everyday violence, alcohol-fueled rage, illness, death, and exceptional historical events like the assassination of Martin Luther King mingle inextricably with the noir conventions of pulp mysteries. In the unfolding investigations, including the unsolved murder of a German neighbor, the monstrous impact of some yet unfathomable damage leads to dangerous and forbidden stories of the Holocaust and sexual slavery.

Monstrosity is also the capacity, then, to sensitively register trauma which is unacknowledged or hidden by others. Yet, our detective of trauma embraces monstrosity as a chosen, desired otherness, agency and freedom ("people should get to be who they are") and extraordinary adventure (the mob pursuing her stands for "mean, ordinary, and boring"), which also undermines the fantastic heights and depths of her vision as perhaps an empowered revenge on reality, a creative or delusional resistance to its frames, which in turn evaporates the narrated characters and events into play and fantasy. Superimposing words and expressive cross-hatched images incongruously on the regular lines of the notebook, every page visualizes this overwriting of the established framework of reality, and the narrative pleasure of pursuing the story keeps this uncertainty in play: a dark concept of trauma as hidden memory and possession is balanced with a light concept of self-healing through limitless transformation and a thrilling irreality of damaging conditions.

\section{Gestural Acts and Physical Sensations}

All comics register an implied embodied contact between the writer and reader through the materiality of the book, as long as the comics appear to be produced through drawing and handwriting and the reader physically handles a material object in the process of reading, turning pages, or even folding out or rotating them. This material contact is both real and, strictly speaking, imaginary, since the mass-produced industrial object can merely remind one of the touch that had to take place, just as the toxic radioactivity actually absorbed by the artist's body in Chernobyl is a sensibility the work is 
infused with since the radioactivity absorbed by the author-reporter's body and original drawings can never be transmitted to the reader of a printed book.. Such implications of embodied contact can be staged, for example in the conspicuous use of a child's handwriting in Ferris's Monsters eschewed in Gloeckner's Diary, or contingent, as in the unintended marks and uncorrected errors due to the circumstances of production, for example in Mazen Kerbaj's Beirut Won't Cry (2007/2017), where the circumstances of the aerial bombardment of Lebanon leave traces - jagged lines and literal stains - on the paper. This implied contact goes beyond the notion that comics combine hand-drawn words and images as material signs of the body's actions and movements. What creates distinctive possibilities for trauma fiction is the association of drawing with intricately connected mental and bodily processes. The act of drawing, as described by British artist Avis Newman, is a mutable process, in which an act of consciousness and a "physical act of mark-making" mutually shape each other (Ramm 2006: 67), activating semiconscious memories and half-thoughts at the limits of self-possession.

This quality of the medium bears on any graphic narration of traumatic events and their aftermath, presented in their various bodily and mental processes and effects, but its effect can be especially powerful in stories where embodiment has a special narrative salience, such as traumas of illness and disability or violent events threatening bodily integrity. David Small's Stitches not only exemplifies such a trauma of illness, but also puts drawing in the center of its story of trauma and recovery during the years of David's childhood and early youth in Detroit. The overwhelming loss in enacted on his body, which is damaged by illness and successively mistreated by his dysfunctional family of medical professionals, and redressed through drawing as a therapeutic means of escape and regained agency, supplying the supplementary voice David's body lacks as a result of losing a vocal cord largely due to his family's inadequate care as he develops throat cancer as a result of his radiologist father's X-ray treatments. These elements of the story evoke a felt connection to the mark-making body, because Small visually conveys a strong sense of identification between the protagonist's body and the book the reader is holding, visualizing the interior spaces of David's body - biological or architectural spaces of lurking danger or a hospitable refuge from the outside world - as spaces behind the "skin" of the two-dimensional paper on which he draws. 
More than a metaphor, this heightened awareness of the physicality of imagemaking can foreground how gestural acts and memories are connected through both conscious and sensory memory - drawing activating dormant muscle memories and a vivid reimagining of a scene (Ramm 2006: 71; Gilmore 160). Variations in technique and texture or inconsistencies between outline and surface can also refocus of the reader's attention on the material contact inherent in production to this end: similarly to Small's consistent mismatch between ink outlines and erratically incomplete watercolor fills in Stitches, Catherine Meurisse's representations of recurring Charlie Hebdo flashbacks and nightmares of flight immerse and partly dissolve her precise ink drawing in an unpredictably spreading graded wash (Meurisse 2016a: 44). In other words, a graphic narrative can foreground its embodied making, engage tactility through its format and alterations of texture and thereby aid the reader's imaginative investment in a fuller sensory recreation of memories, a felt surplus to the meaning acquired through the distant sense of sight.

Trauma theory continues to evolve through new ways of understanding the process of traumatization and recovery, as our knowledge of the traumatic process inevitably changes with advances in cognitive science, while profound changes in media exposure and use and the shifting dynamics of a global exchange of information shape what counts as trauma and how it can be voiced and acknowledged. An altered or improved knowledge of the importance of images, narration, and the links between the two in trauma may, in turn, shed new light on comics' affinity with trauma in its complex form of telling stories with images.

\section{References}

Bainbridge, J. (2009) “'Worlds Within Worlds': The Role of Superheroes in the Marvel and DC Universes," in A. Ndalianis (ed.). The Contemporary Comic Book Superhero. New York: Routledge. 64-85. 
Balaev, M. (2014) "Literary Trauma Theory Reconsidered," in M. Balaev (ed.) Contemporary Approaches in Literary Trauma Theory, Palgrave. 1-14.

Bazambanza, R. (2005). Smile through the Tears: The Story of the Rwandan Genocide. Montreal: Les Éditions Images.

Bukatman, S. (2009) "Secret Identity Politics," in A. Ndalianis (ed.) The Contemporary Comic Book Superhero. New York: Routledge. 109-125.

Caruth, C. (1996) "Trauma and Experience," in Trauma: Explorations in Memory. Baltimore: Johns Hopkins Univ. Press. 3-12.

Chaney, M. (2011) “The Animal Witness of the Rwandan Genocide,” in M. Chaney (ed.) Graphic subjects: critical essays on autobiography and graphic novels. Madison, Wisconsin: University of Wisconsin Press. 93-100.

Chute, H. (2008) "Comics as Literature?: Reading Graphic Narrative." PMLA 123:2 (March): 452-65.

---- (2016) Disaster drawn: Visual witness, comics, and documentary form. Cambridge, Mass: The Belknap Press of Harvard University Press.

Craps, S. (2014). "Beyond Eurocentrism: Trauma Theory in the Global Age," in G. Buelens, S. Durrant, and R. Eaglestone (eds.) The future of trauma theory: Contemporary literary and cultural criticism.. New York: Routledge. 45-61.

Dony, C. and C. van Linthout (2010) "Comics, trauma, and cultural memory(ies) of 9/11," inJ. Goggin and D. Hassler-Forest (eds.)The Rise and Reason of Comics and Graphic Literature: Critical Essays on the Form. London: McFarland Press. 178-188.

Earle, H. (2017) Comics, Trauma, and the New Art of War, Univ. Press of Mississippi.

Ferenczi, S. (1994) “Two types of war neuroses" [1916/17], in J. Rickman (comp.) Further Contributions to the Theory and Technique of Psychoanalysis, London: Karnac Books, 124-141.

Ferris E. (2017). My Favorite Thing Is Monsters. Seattle: Fantagraphics.

Geroulanos, S. and T. Meyers(2018). The Human Body in the Age of Catastrophe: Brittleness, Integration, Science, and the Great War, Chicago: Chicago UP.

Gibbs, A. (2014) '"The problem is, I'm not sure I believe in the thunderclap of trauma": aesthetics of trauma in contemporary American literature,' in T. Bényei and A. 
Stara (eds.) The edges of trauma: Explorations in visual art and literature, Newcastle upon Tyne: Cambridge Scholars Publishing. 148-168.

Gilmore, L. (2011) "Witnessing Persepolis: comics, trauma and childhood testimony," M. Chaney (ed.) Graphic subjects: critical essays on autobiography and graphic novels. . Madison, Wisconsin: University of Wisconsin Press. 157-163.

Gloeckner, P. (2015 [2002]) The diary of a teenage girl: an account in words and pictures, revised edition. Berkeley: North Atlantic Books.

Groensteen, T. (2009) “The Impossible Definition," in J. Heer and K. Worcester (eds.) A Comics Studies Reader, University Press of Mississippi. 124-131.

Hippolyte and P. de Saint-Exupery (2014) La fantaisie des Dieux: Rwanda 1994. Paris: Les Arènes.

Huyssen, A. (2003) Present Pasts: Urban Palimpsests and the Politics of Memory. Stanford: Stanford UP.

Kansteiner, W. (2006) "Genealogy of a category mistake: a critical intellectual history of the cultural trauma metaphor," Rethinking History, 8:2, 193-221.

Kerbaj, M. (2007) Beyrouth, juillet-août 2006. Paris: L'Association.

--_ (2017) Beirut Won't Cry. Lebanon's July War: A Visual Diary. Seattle: Fantagraphics Underground.

Køhlert, F. B. (2015). Working it Through: Trauma and Autobiography in Phoebe Gloeckner's A Child's Life and The Diary of a Teenage Girl, South Central Review 32.3 124-142.

Konner, M. (2007) "Trauma, Adaptation, and Resilience: A Cross-Cultural and Evolutionary Perspective," in L. Kirmayer, R. Lemelson, and M. Barad (eds.) Understanding Trauma: Integrating Biological, Clinical, and Cultural Perspectives, Los Angeles: University of California Press, 300-338.

LaCapra, D. (2000) Writing History, Writing Trauma. Johns Hopkins University Press.

Lepage, E (2013). Un printemps à Tchernobyl. Paris: Futuropolis.

Luckhurst, R. (2013). "Future Shock: Science Fiction and the Trauma Paradigm," in G. Buelens,, S. Durrant, and R. Eaglestone (eds.) The future of trauma theory: Contemporary literary and cultural criticism. London: Routledge. 157-167. 
Meurisse, C. (2016a) La légèreté. Paris: Dargaud. Preface by P. Lançon.

--_ (2016b) The Lightness. Harper's. December 2016. 55-57.

Mikkonen, K. (2015). "Subjectivity and Style in Graphic Narratives," inD. Stein and J.N. Thon (eds.) . From Comic Strips to Graphic Novels: Contributions to the Theory and History of Graphic Narrative. Berlin/Boston: De Gruyter. 101-125.

Nakazawa, K. (1982) I Saw It: The Atomic Bombing of Hiroshima: A Survivor'sTrue Story. San Francisco: EduComics.

----- (2016) Barefoot Gen. 1, A cartoon story of Hiroshima. Translated by Project Gen. San Francisco, CA: Last Gasp.

Neufeld, J.. (2009) A.D.: New Orleans after the Deluge. New York: Pantheon.

Ramm, A.. (2005) "What is drawing? Bringing the art into art therapy," International Journal of Art Therapy, 10:2, 63-77.

Radstone, S. (2007). Trauma Theory: Contexts, Politics, Ethics. Paragraph 30:1, 9-29.

Sacco, J. (2004) The Fixer: a story from Sarajevo. London: Jonathan Cape.

Shively, S. B. and D. P. Perl (January 01, 2012). "Traumatic brain injury, shell shock, and posttraumatic stress disorder in the military--past, present, and future," The Journal of Head Trauma Rehabilitation, 27, 3.

Small, D. (2009) Stitches: A Memoir. New York: Norton.

Spiegelman, A. (1986) Maus: a survivor's tale. I. My Father Bleeds History. New York: Pantheon.

-----. (1991) Maus: a survivor's tale. II. and here my troubles began. New York: Pantheon.

----- (2004). In the Shadow of No Towers. New York: Pantheon.

Stassen, J. -P.. (2000) Déogratias. Marcinelle: Dupuis.

--- (2006) Deogratias: A Tale of Rwanda. Translated by Alexis Siegel. New York: First Second Press.

Tran, G. B. (2010). Vietnamerica: A Family's Journey. New York: Villard. Una [pseudonym] (2015). Becoming Unbecoming. Oxford, UK: Myriad. 